E.L.U.A., 1, 1983, págs. 263-302

\title{
LA ESTRUCTURA LÉXICO-SEMÁNTICA DE LA COORDINACIÓN
}

\author{
Juan Luis Román del Cerro \\ (Universidad de Alicante)
}

\section{INTRODUCCIÓN Y CUESTIONES DE METODOLOGÍA ANALÍTICA}

En este artículo se ha puesto por escrito una parte de la investigación léxico-semántica que llevo a cabo sobre la estructura oracional en general. $\mathrm{Y}$ espero en breve tiempo poder presentar un trabajo completo en donde se incluya la subordinación y la relativización.

El estudio comprende tres apartados fundamentales. En el primero, se establece la hipótesis general de la estructura léxico-semántica de la coordinación. El punto de partida es el predicado semántico ALTERNATIVA, que presenta la alternativa entre dos o más elementos, en nuestro caso, oraciones. La alternativa puede presentar la modalidad de inclusión, ALTERN. VEL, en donde la posibilidad $A$ incluye la posibilidad $B$, que presenta el modelo de la disyuntiva incluyente. La alternativa puede presentarse también en su modalidad excluyente, ALTERN. AUT, en donde la posibilidad A excluye la posibilidad B, cuyo modelo es el de la disyuntiva excluyente. De ahí pasamos a agotar el predicado ALTERNATIVA sometiéndolo a la operación de Negación. Al negar la alternativa excluyente, NEG/ALTERN. AUT, se manifiesta el sentido adversativo pero; y al negar la alternativa incluyente se configura el sentido adversativo sino. $Y$, por último, se cierra el ciclo negando la disyunción de negaciones, con lo que se produce el sentido conjuntivo, es decir, la oración copulativa que adiciona $\mathrm{A}$ y $\mathrm{B}$. 
Estas cinco operaciones consumen todas las posibilidades del predicado semántico ALTERNATIVA, cerrando, pues, su ciclo posible. Pues bien, nuestra hipótesis es que la coordinación no es otra cosa que el desarrollo cíclico del predicado ALTERNATIVA, lo que conlleva la ventaja de definir formalmente la estructura coordinada con los límites exactos entre coordinación y subordinación.

Una vez desarrollada la hipótesis general hacemos una restricción de la misma, considerando que la alternativa o coordinación no es sólo de proposiciones sino que también se da entre los performativos de dichas proposiciones, entendiendo genéricamente por performativo, la intención comunicativa del hablante. La exposición estructural de esta idea se plasma en el adverbial del performativo en oposición al adverbial de la proposición.

El tratamiento de los performativos en la coordinación nos conduce a descubrir una anomalia en los mismos: no todos los performativos permiten combinarse entre sí, en las cinco estructuras coordinantes propuestas. Estas anomalías, que acontecen en la coordinación de performativos heterogéneos, se ponen de manifiesto y se establece la regla que los condiciona.

Por último, se estudia el problema de la yuxtaposición. Una vez formalizada la estructura del asíndeton se constata su equiparación semántica con la copulativa. El caso particular de las distributivas se resuelve también con la misma configuración semántica.

Todo este esquema general del artículo quedaria absolutamente desvirtuado si no acometiéramos lo que es central y definitivo, delimitar el objeto del análisis.

Por desgracia, la bibliografia que trata cuestiones de léxicosemántica, desde nuestro punto de vista, suele olvidar o desdeñar hecho tan esencial. Difícilmente podemos acometer la aventura de adentrarnos en las entrañas mismas del significado del léxico, sin definir el objeto mismo del análisis. Para ello, es del todo necesario, desde la perspectiva epistemológica, distinguir dos conceptos esenciales: los valores léxicos que virtualmente aportan las palabras y los valores con que se implementan, gracias al discurso o a los conocimientos generales que se poseen.

Esta distinción se circunscribe a lo que podriamos llamar el valor mínimo común denominador de una palabra, en oposición a los valores sobreañadidos que inferencialmente puede recibir toda una proposición; y, por lo mismo, atribuirle a cada parte de dicha proposición el valor implementado.

La distinción será pertinente en el caso de que las palabras puedan presentar isotopias en sus significados y exista un método por el que se 
implementen los valores léxicos. Lo primero es un hecho incontestable que pertenece al sistema económico del lenguaje; y lo segundo, la implementación, se produce por la capacidad inferencial de la mente humana. Esta capacidad inferencial tiene la virtualidad de hacer que 1 +1 no sumen 2 sino que puedan sumar 3 , logrando con ello una redefinición de las relaciones léxicas primarias.

Comencemos, pues, por consignar qué entendemos por significado léxico propiamente dicho. Podriamos definirlo por la parte del significado necesaria y suficiente para la existencia de una voz léxica, que está presente en todos los usos de una palabra y, a falta de la cual, el sonido de la voz léxica se convierte en un sonido privado de significado. En el caso de que entre dos interlocutores el significado léxico de una palabra sea distinto, la comunicación se bloquea, hecho que no ocurriría con la parte de los significados léxicos implementados.

Por su lado, el sistema inferencial, al hacer posible una hipersignificación, sigue fundamentalmente dos caminos: la vía de la inferencia discursiva y la vía de la inferencia enciclopédica.

Digamos, en general, como opera la enciclopedia en la implementación del valor léxico (CASTELFRANCHI, 1975; POSNER, 1980; ROMAN, 1981, 90). Consideremos para ello las siguientes frases,

(1) ¿Qué hora es... Son las cinco.

(2) ¿Cuándo nace el niño? -El niño nace en verano.

(3) ¿Cuándo llega el hombre a la luna? -El hombre /lega a la luna en la década de los setenta.

Si prestamos atención a los verbos en cursiva son, nace y llega podemos comprobar que los tres están en presente de indicativo. Supongamos que queremos averiguar la estructura general del presente; tendríamos que crear una hipótesis que fuera válida en las tres frases. Sin embargo, que duda cabe que en la frase (2) hemos implementado el significado del presente en futuro o posterioridad y en (3) en un pasado o presente histórico. Estos significados de pasado y futuro que puede recibir el presente se deben a la inferencia que hace el hablante desde los conocimientos enciclopédicos que culturalmente ha adquirido sobre las estaciones del año y sobre los viajes lunares.

Ahora bien, si el objeto de estudio es la estructura semántica del morfema de presente, tendré que configurarla según los valores siempre presentes en cualquier uso posible y a partir de ahí explicar qué isotopías se pueden presentar. Si por el contrario, inicio el estudio del presente y no lo aislo del significado de pasado o futuro será metodológicamente imposible que se explique qué significa el morfema de presente. 
Pues esto mismo es aplicable a los valores léxicos coordinantes. Consideremos, para ello, la frase

\section{(4) Lo buscaban y lo encontraron}

Nuestro objetivo, al considerar esta frase, es hallar la estructura de la copulativa. Analizando la frase, constatamos que el hablante ha generado una estructura coordinada, no subordinada, y que las dos enunciaciones están adicionadas por la copulativa y. Además, conocemos que el hablante ha renunciado a utilizar una conjunción conclusiva, opción que podía ser elegida.

Sin embargo, muchos manuales afirman que esta oración es consecutiva. ¿En qué sentido se puede afirmar que el hablante ha generado una relación consecutiva? Desde luego, no porque el hablante haya generado una estructura consecutiva, a la que explícitamente ha renunciado, sino porque el oyente hace una inferencia enciclopédica, y sobreimpresiona una relación causa/efecto entre buscar y encontrar, debido a que tiene almacenado en su memoria un conocimiento del tipo "hay que buscar para encontrar», por sus experiencias habituales. Pero ésta es una posible interpretación del oyente, no es la generación estructural que ha hecho el hablante. Sin embargo, sí que es pertinente el construir una hipótesis tal de esta voz léxica que explique y permita su implementación en otros sentidos, y que no desvirtúe nunca su estricto valor léxico.

Aún más, ¿qué diríamos de la frase

\section{(5) No lo buscaban y lo encontraron}

en donde es claro el sentido copulativo y mi enciclopedia no permite inferir el sentido consecutivo? ¿En base a qué analizamos (4) como consecutiva y (5) como copulativa? Desde luego, no porque el hablante haya generado la estructura consecutiva, sino porque el oyente la produce inferencialmente. $Y$, desde luego, se trata, en primer lugar, y como conditio sine qua non, de establecer cuál es el significado de la estructura coordinada en su generación, para posibilitar después el estudio de la implementación inferencial que pueda hacer el oyente.

Formalmente podríamos simbolizarlo siguiendo el formato presentado por CASTELFRANCHI y PARISI (1980, 85 y ss.): $C_{1}, C_{2} \ldots$ representan unidades cognoscitivas que a su vez están constituidas por un predicado lógico y por uno o más argumentos, requeridos intrínsecamente por tal predicado. A su vez, los argumentos quedan simbolizados por una $X$, con un subíndice numérico. En el caso de que dos o más $X$ tengan el mismo 
subíndice, son la misma entidad. Si tienen subíndice diverso, son entidades diversas.

Según esto, la frase (4) puede formalizarse

ESTRUCTURA SEMÁNTICA GENERADA EN (4)

$$
\begin{aligned}
& C_{1}: X_{1} \text { BUSCA } X_{2} \\
& C_{2}: X_{1} \text { ENCUENTRA } x_{2} \\
& C_{3}: C_{1} \text { AÑADE } C_{2}
\end{aligned}
$$

\section{ESTRUCTURA INFERENCIADA ENCICLOPÉDICAMENTE}

$$
\mathrm{C}_{4}: \mathrm{C}_{1} \text { CAUSA } \mathrm{C}_{2}
$$

Según esto, se puede formalizar el objetivo de la investigación que realizamos diciendo que versa sobre la estructura de $\mathrm{C}_{3}$, lo que excluye, por lo mismo, recurrir a consideraciones de $\mathrm{C}_{4}$.

La segunda vía por la que el oyente puede implementar los significados léxicos, se da a través de las inferencias discursivas. Estas inferencias se producen por el hecho de que la frase generada esté precedida de otras frases en el discurso.

Si enunciamos una frase narrando que,

(6) Dos ciervos bebieron en el arroyo, miraron alrededor y salieron corriendo

podemos interpretar que se enumeran tres hechos sucesivos en el tiempo y sin otro tipo de relación. En cuyo caso, la conjunción y será interpretada como copulativa.

Ahora bien, hagamos preceder a esta frase de un contexto en donde se haya narrado que una manada de leones estaba bebiendo en el mismo arroyo. En este supuesto, la mente hace una inferencia y le da un significado de consecuencia a la frase $y$ salieron corriendo, porque es sabido, enciclopédicamente, que los leones se comen a los ciervos. Si queremos por lo mismo atribuir a la conjunción $y$, que es quien vehicula la estructura coordinada copulativa, un significado consecutivo, estaremos cometiendo un error. En primer lugar, porque y salieron corriendo no es la consecuencia de bebieron..., miraron, sino de un contexto anterior que aporta, por un lado, un dato y presupone otros conocimientos: informa de que una manada de leones estaba bebiendo, y presupone, enciciopédicamente, que es habitual que los leones se coman a los ciervos. De todo ello se extrae la consecuencia y 
salieron corriendo. $Y$ en segundo lugar, también se comete un error, porque no es sólo la conjunción y la que se carga de significado consecutivo; dicho significado no necesita de la conjunción $y$, puede construirse paratácticamente, porque en realidad es un nexo no léxico inferido por la mente y que se establece implícitamente entre salir corriendo $y$ el discurso anterior.

Lo único, pues, que cabe resolver es que dicha frase narra aditivamente varias acciones y que, en virtud de las inferencias discursivas que hace la mente, una parte de esa frase tiene relaciones consecutivas inferenciadas con algún contexto precedente. Pero, en ningún caso, ni se genera, ni se produce ninguna estructura consecutiva.

Como consecuencia de todo ello, y dado que el objetivo del análisis es el conocimiento de la estructura general de las oraciones, en este caso de la coordinación, tendremos que acometer en primer lugar, y como conditio sine qua non, el estudio del significado léxico de dichos relacionantes, y en un segundo momento, siempre posterior, explicar cómo desde esta hipótesis estructural mínima se pueden implementar otros significados; en otras palabras, si la configuración estructural de los sentidos virtuales es tal que puede dar razón de los sentidos coyunturales que inferencialmente aporta la textuación de las frases.

Pues bien, el objeto de nuestro análisis queda formalmente delimitado al estudio de la estructura oracional de la coordinación, pero de su estructura léxica estrictamente, y no al estudio de los posibles valores coyunturales que inferencialmente puedan completarlo. Sin embargo, no renunciamos esporádicamente a mostrar la bondad del modelo propuesto, haciendo resaltar con qué facilidad desde la hipótesis nuestra se puede hacer la implementación de una coordinada a sentidos adverbiales.

En conclusión, podemos formalizar la distinción precedente, basada en la capacidad inferencial, de la forma siguiente, (CASTELFRANCHI, PARISI, 1980, 39): en un momento $T_{0}$ los conocimientos de la mente contienen un número $N$ de informaciones, y en el momento $T_{1}$, consiguiente al ingreso en la mente de una determinada frase, los conocimientos no contienen sólo $N+1$ informaciones - es decir, no se añade sólo la información directamente comunicada por la frase- sino que contienen un número $N+M(M>1)$ de informaciones, en donde las informaciones excedentes que se añaden son generadas por la interacción entre la información comunicada en la frase y los conocimientos ya poseídos por la mente, discursiva o enciclopédicamente. Desde nuestra visión, cualquier intento de formalizar las estructuras léxicas y, consiguientemente, las relaciones interoracionales debe versar esencial- 
mente sobre el estudio de 1 en $N+1$, y no de $M$, que es un valor mayor que 1.

Ser negligente con este principio epistemológico lleva inexorablemente a la mixtificación y a la confusión, y, por lo mismo, a la incapacidad de comprensión del fenómeno. Paradigmáticamente, podríamos referirnos a la ciencia médica que sólo estudiara la sintomatología de la enfermedad, renunciando a conocer la estructura misma de quien causa el sindrome y los mecanismos íntimos que desencadenan los síntomas.

La seriedad de esta advertencia pone en su exacto lugar el contenido de nuestro análisis. Conseguir la estructura íntima del léxico es, hoy por hoy, un camino que se recorre; sin duda, nuestro intento es una hipótesis inadecuada, pero al menos tiene la virtud de ser una formalización precisa en cuanto al objetivo del estudio y en cuanto a la hipótesis misma. Por ello, creo que es oportuno aplicarle el principio que Chomsky $(1957,5)$ reclama para la Lingüística: «sometiendo una formulación precisa, pero inadecuada, a una conclusión inaceptable, a menudo llegamos a revelar las fuerzas exactas de su insuficiencia, y, por lo mismo, a ganar una comprensión más profunda de los hechos".

\section{HIPÓTESIS GENERAL DE LA ESTRUCTURA LÉXICO-SEMÁNTICA DE LA COORDINACIÓN}

El esquema lógico de la coordinación parece ser bastante unitario ya que todo él está basado en el concepto de alternativa o disyunción. Este concepto lo traducimos lingüísticamente por el predicado semántico ALTERNATIVA, que se lee " $x$ es alternativa de $y$ ", y puede tomar la forma superficial de la conjunción 0 .

El cálculo proposicional de la disyunción especifica que ésta se puede dar de dos formas, como disyuntiva incluyente o excluyente:

\section{DISYUNTIVA INCLUYENTE}

Alternativa incluyente que se denota mediante la conjunción latina $v e l$, de ahí el símbolo $p \vee q$, que se lee $p$ vel $q, p \circ q$. Esta alternativa incluyente aparece en el ejemplo:

(7) Tienen derecho a pensión los emplèados con más de 30 años de servicio o con más de 65 años de edad.

en donde se dice que para tener derecho a pensión hay dos alternativas, de forma que se puede dar una de ellas o bien las dos, no exclu- 
yéndose entre sí en ningún caso. La representación de este sentido le corresponde al predicado semántico ALTERNATIVA VEL, siendo la configuración de la frase

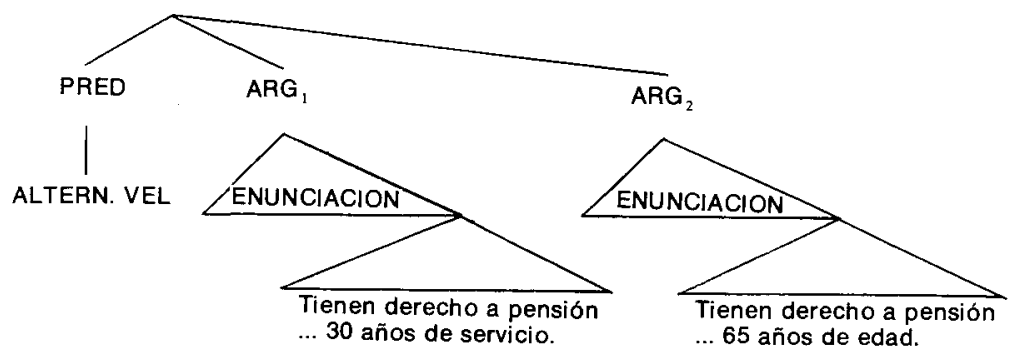

cuya lectura es: la alternativa, te comunico que tienen derecho a pensión los empleados con más de 30 años de servicio incluye la alternativa, te comunico que tienen derecho a pensión los empleados con más de 65 años de edad.

Hay un hecho estructural en esta representación, la estructura adverbial del performativo del predicado ALTERN.VEL, al que le dedicaremos especial atención en el apartado 2. del trabajo.

\section{DISYUNTIVA EXCLUYENTE}

La alternativa puede tomar el significado de exclusión o alternativa excluyente, que se denota mediante la conjunción latina aut, de ahí el símbolo $p A q, p \circ q$. Esta alternativa excluyente aparece en el ejemplo,

(8) Iré al cine o a los toros, para pasar la tarde

en donde se dice que para pasar la tarde se ofrecen dos posibilidades a elegir una, y la elección de una excluye a la otra. El predicado que simboliza este significado es ALTERNATIVA AUT, siendo la configuración semántica de la frase, 


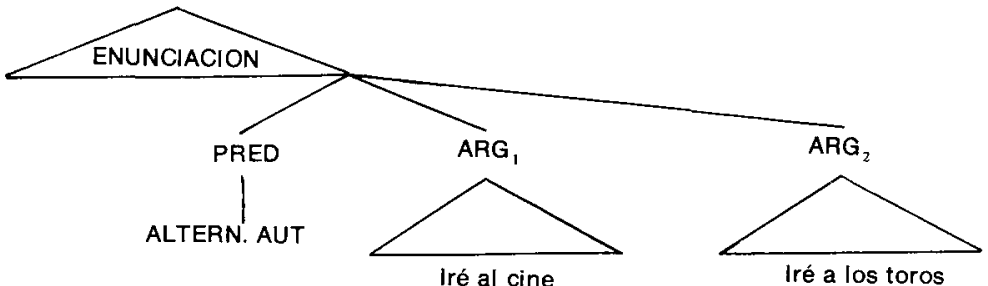

cuya lectura es: la alternativa iré al cine... excluye la alternativa iré a los toros...

En oposición a la disyuntiva incluyente aquí se da la estructura adverbial de la proposición, y no del performativo.

\section{ADVERSATIVA PERO}

Si efectuamos la negación de la alternativa excluyente, aparece el sentido de no exclusión, que configura el significado adversativo pero. Así una frase como,

(9) Jugaremos el partido pero lo jugaremos a nuestro modo tiene la configuración semántica,

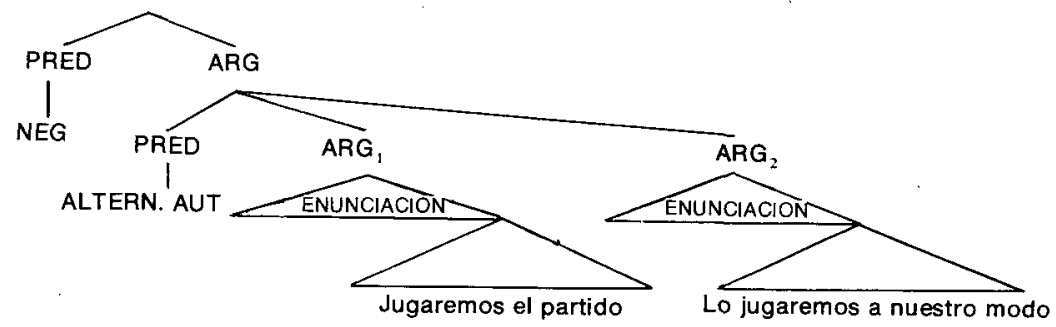

cuya lectura es: la alternativa, te comunico que jugaremos el partido no excluye que te comunique que lo jugaremos a nuestro modo. $\mathrm{Y}$, además, queremos advertir aquí la estructura adverbial del performativo. 


\section{ADVERSATIVA SINO}

Si efectuamos, por contra, la negación de la alternativa incluyente, aparece el sentido sino, a condición de que el $\mathrm{ARG}_{2}$ sea negativo. Según esto, una frase como,

(10) No retrocederemos sino que atacaremos

tiene la siguiente configuración semántica

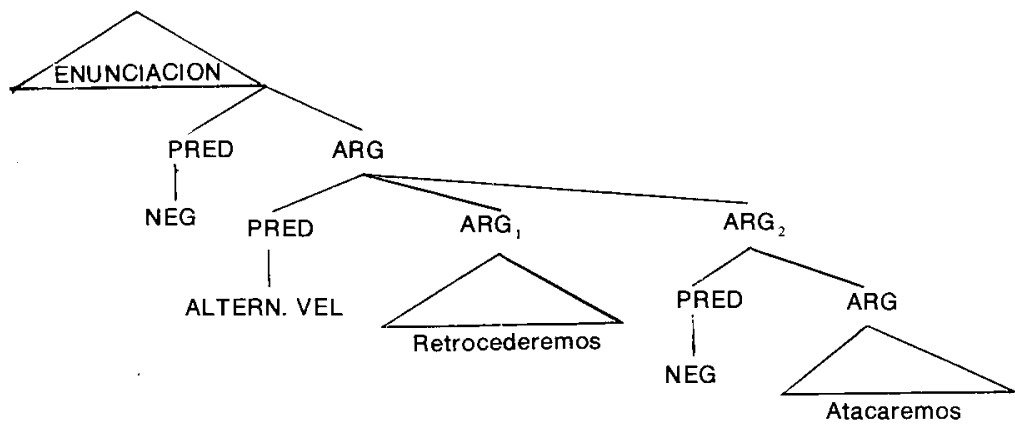

cuya lectura es: niego que retrocedamos o no ataquemos. (Advertimos de ahora en adelante que al emplear la expresión «niego que» incluimos el performativo, "te comunico la negación de..."). Queremos, por último, notar que la estructura es adverbial de la proposición.

\section{OBSERVACIONES A LAS ADVERSATIVAS PERO y SINO}

Una vez propuestas las estructuras correspondientes a pero y sino como los dos tipos negativos de la disyunción, conviene hacer algunas advertencias y establecer ciertas relaciones o distancias entre ambos tipos.

En primer lugar, observamos que nuestro modelo estructural permite que cada proposición sea de signo contrario al de los ejemplos propuestos. Así son gramaticales las siguientes frases (11) y (12):

(11) No tenía dinero pero supo arreglárselas

cuya primera proposición es negativa, y que obtiene la configuración, 


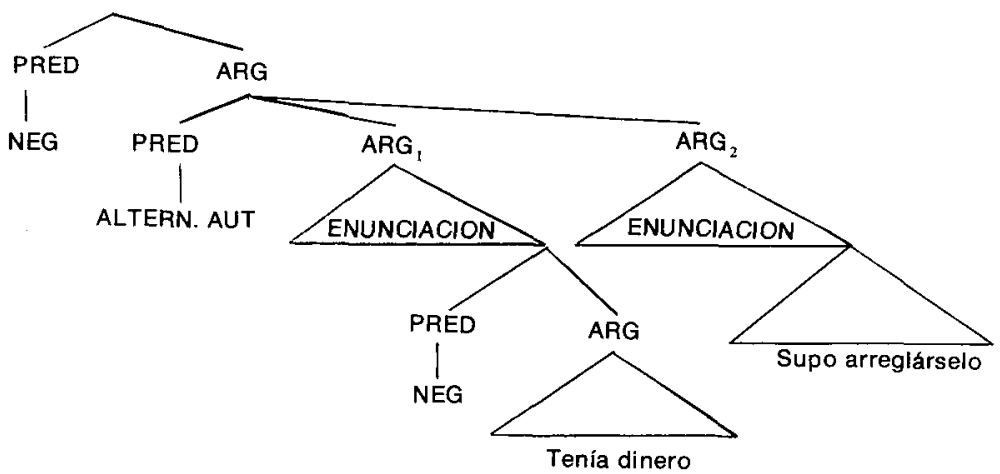

lectura: la alternativa, te comunico que no tenia dinero no excluye que te comunique que supo arreglárselas. $\mathrm{Y}$.

(12) Tenia dinero pero no supo arreglárselas

cuya obvia representación tiene la proposición del $A R G_{2}$ negativa.

Para el caso de la adversativa sino, las proposiciones también pueden presentar la negación o la afirmación en cualquiera de las dos proposiciones. Y para la comprensión suficiente de este hecho conviene considerar los siguientes ejemplos: «Supongamos que existe una expectativa de que el ejército de Julio César pase al ataque en las Galias". Se tiene, pues, una presuposición "se espera que el ejército ataque», y la respuesta a esas expectativas es,

(13) No ataca sino que retrocede

o bien,

(14) No sólo no ataca sino que retrocede

frases que pueden considerarse fundamentalmente equivalentes -si exceptuamos el posible énfasis que conlleva la expresión no sólo-, puesto que lo propuesto en ambas frases y lo presupuesto coincide. Según esto, podemos avanzar que las correlaciones de este tipo adversativo no son no... sino, para cada una de las proposiciones, sino más bien no sólo... sino, aunque, la presencia del correlativo no sólo no tenga que ser siempre explícita.

Dado, pues, el carácter eminentemente de apoyatura que tiene la 
expresión no sólo y que en modo alguno modifica el sentido de sino, podemos construir cuatro modelos en donde se varíe el signo positivo o negativo de las proposiciones:

No sólo $(+)$ sino $(+)$ :No sólo ataca sino que vence.

No sólo (-) sino (-) :No sólo no ataca sino que no atacará.

No sólo $(+)$ sino (-) :No sólo ataca sino que no retrocede.

No sólo $(-)$ sino $(+)$ :No sólo no ataca sino que retrocede.

La frase del primer modelo

(15) No sólo ataca sino que vence.

sin duda traduce una correlación entre dos miembros, en este caso proposiciones, que pueden ser expresadas en otras lenguas, asi en latín, por et...et o en griego, por kai...kai, etc.; de modo que podríamos considerar que la belleza y simplicidad estructural de estas correlaciones, en castellano han sufrido temporalmente un proceso de lexicalización cercano al barroquismo. Esto nos lleva a considerar que es el sentido copulativo el que está inter-relacionando ambas proposiciones. La estructura copulativa, que nos vemos obligados a avanzar aqui, es del tipo NEG/ALTERN. VEL (NEG,$\left.N_{1} \mathrm{NE}_{2}\right)$, que al aplicarse a la frase (15) da la siguiente configuración,

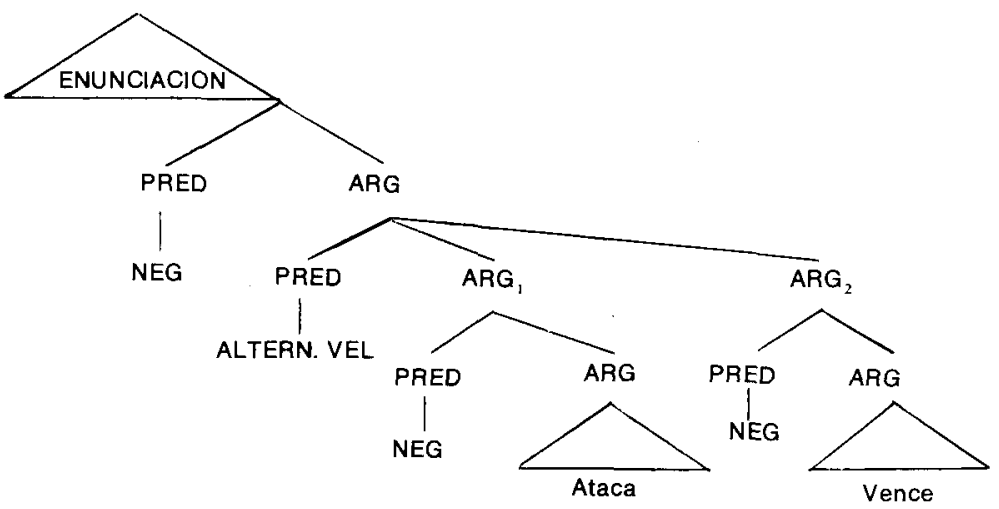

cuya lectura es: niego que no ataque o no retroceda.

Según esto, cuando las dos proposiciones son de signo positivo, el sentido profundamente copulativo de la relación se hace patente, mostrando la cercanía y semejanza de lo adversativo y copulativo. 
El segundo modelo representado por

(16) No sólo no ataca sino que no atacará

se configura lógicamente

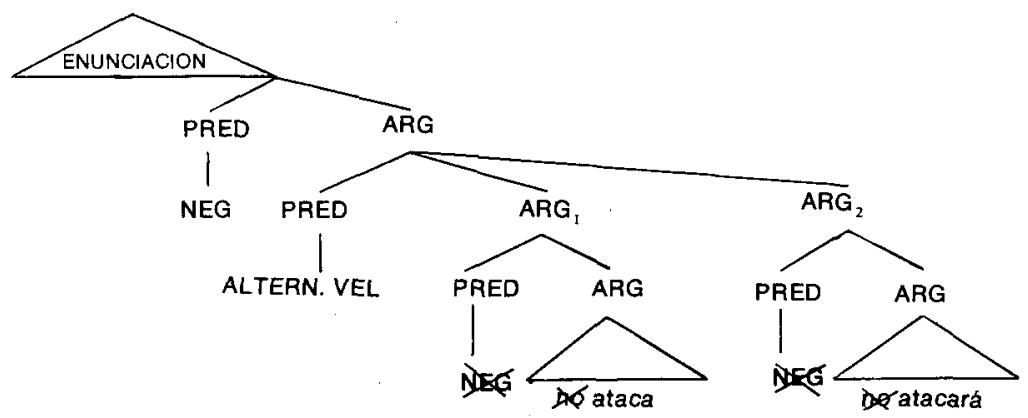

que se lee: niego que ataque o que atacará.

El tercer modelo, que representa la frase,

(17) No sólo ataca sino que no retrocede.

se configura

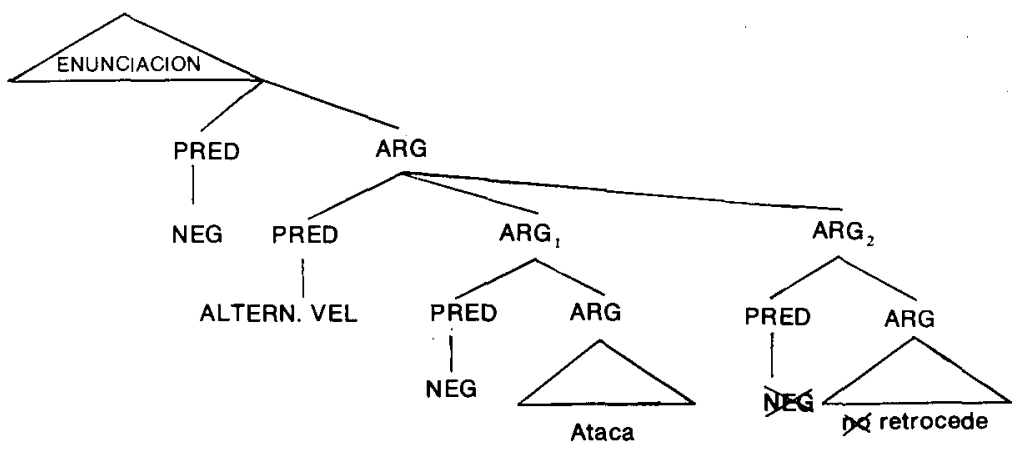

y se lee: niego que no ataque o retroceda. 
El último modelo, representado por la frase,

(18) No sólo no ataca sino que retrocede.

se configura

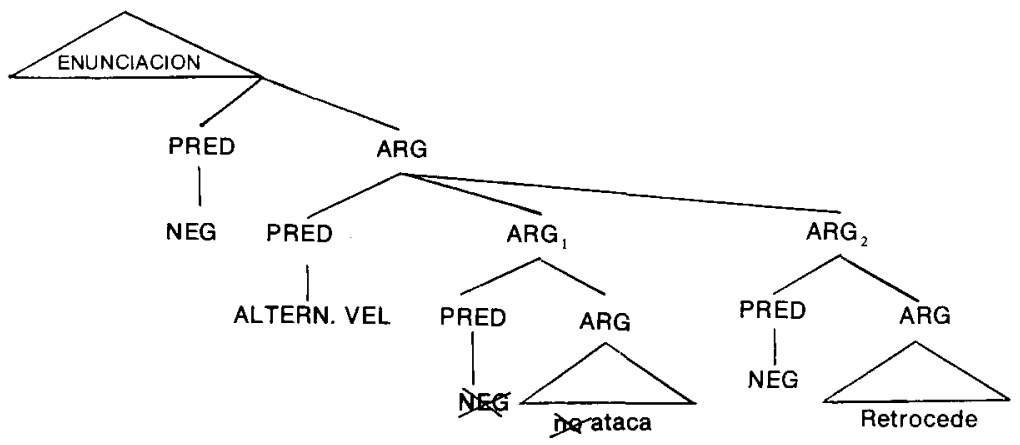

que, al reducir las negociaciones contiguas, se identifica con el modelo adversativo sino, ofrecido como hipótesis al principio: NEG/ ALTERN. VEL / NEG.

De estas formalizaciones se desprenden dos hechos, el primero es la gran cercanía estructural de la copulativa y la adversativa sino, mostrando cómo la coordinación, en su génesis, no es sino un todo continuo, sin zonas separadas, en donde, gracias a la incidencia sutil y variable de la negación, se nos transporta desde la disyunción a la adversación y a la conjunción.

La segunda consideración impugna, por así decir, el consenso establecido sobre la adversativa sino, que postula que la oración matriz debe ser negativa, y convierte la correlación en no...sino, cuando hemos mostrado que la correlación es no sólo...sino. Porque, que sean gramaticales frases como No ataca sino que retrocede y agramaticales *Ataca sino que vence, o bien *Ataca sino que retrocede, no prueba la necesidad de la negatividad de la matriz, ya que No sólo ataca sino que vence o bien No sólo ataca sino que no retrocede son frases cuya oración matriz no es negativa desde ningún punto de vista. La única diferencia entre estos dos tipos de frases estriba en que el primero no necesita el correlativo no sólo para ser gramatical, aunque lo admite, mientras que el segundo lo necesita explícitamente para serlo. Con ello el problema se reduce a conocer las condiciones de uso del no sólo, pero nunca a postular la negatividad de la oración matriz. 
Por último, queremos señalar que la hipótesis estructural de pero que hemos propuesto solventa satisfactoriamente, a nuestro modo de ver, el concepto de "superioridad de la matriz" que para la adversativa pero postulan ANSCOMBRE Y DUCROT (1977); asi el ejemplo propuesto por BOSQUE $(1980,138)$,

${ }^{*}$ No es probable pero es cierto

cuya agramaticalidad se basa en que la primera proposición no es argumentativamente superior, queda asumida dentro de las restricciones de nuestro modelo, siendo la representación

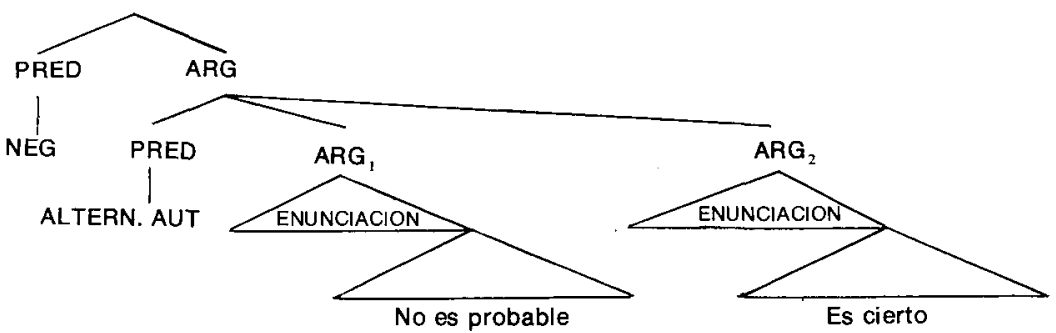

cuya absurda lectura es: la alternativa, te comunico que no es probable no excluye que te comunique que es cierto, lo que muestra la inadecuación de tal estructura. Según nuestro modelo, formalmente el $A_{R} G_{1}$ no excluye el $A R G_{2}$, sin embargo, en el ejemplo citado se intenta colocar un material semántico tal que el $A R G_{1}$ excluya el $A R G_{2}$, hecho que la estructura rechaza.

\section{COPULATIVA: $\mathbf{Y}, \mathbf{N I}$}

Una vez negadas las alternativas vel y aut, en cuya estructuración se basa el sentido adversativo, al predictado semántico NEG le podemos hacer concurrir doblemente, negando la disyunción de negaciones, cuyo resultado conjuntivo se lee, niego no $p$ o no $q$, y cuya traducción lingüistica puede parafrasearse como niego que no llore o no ría, es decir, llora y rie. La configuración semántica de la frase

(20) Juan rie y Pedro llora

corresponde a 


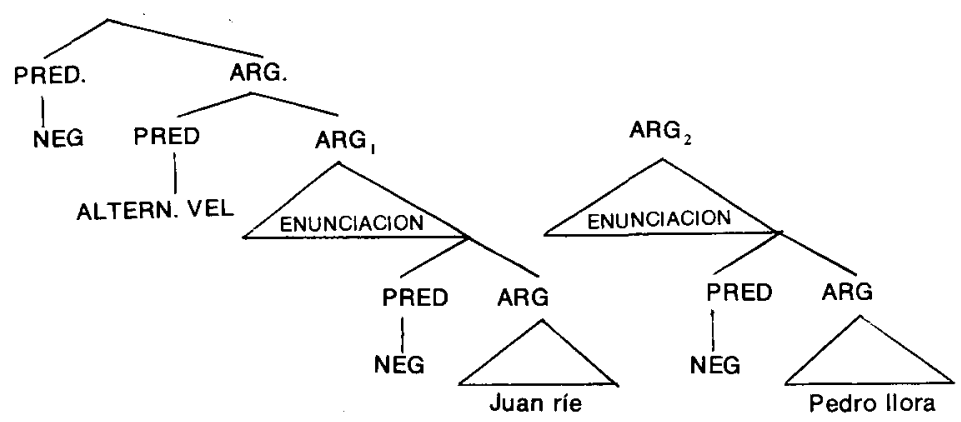

y cuya lectura es: Niego que Juan no ría o Pedro no llore, que admite la configuración simplificada

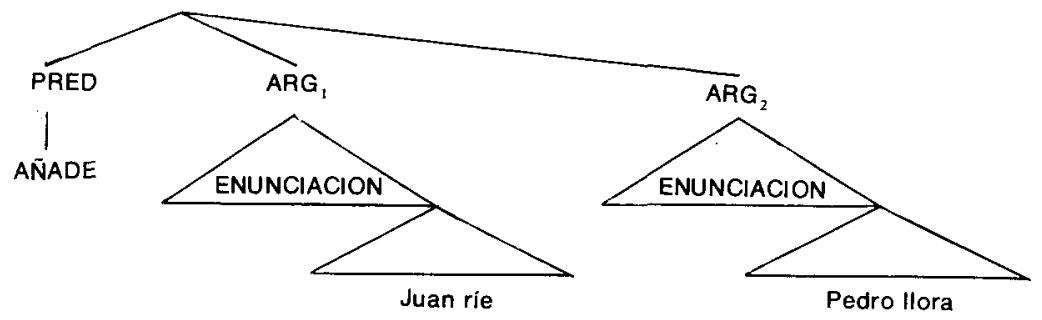

También quiero hacer notar que la estructura es adverbial del performativo.

Por otro lado, el relacionante ni que encontramos en la frase

(21) Ni retrocedemos, ni atacamos

permite la configuración

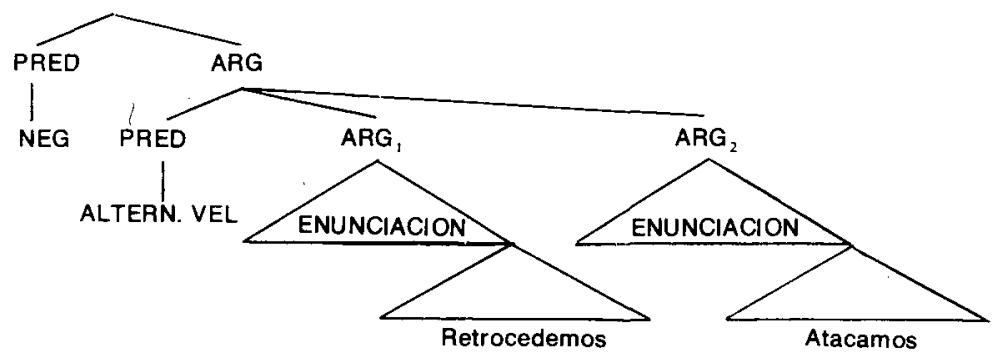


cuya lectura es: Niego que retrocedamos o ataquemos.

\section{RESUMEN LÓGICO-PROPOSICIONAL}

El cálculo proposicional y las operaciones lógicas implicadas en la coordinación vienen a mostrar, en resumidas cuentas, que la coordinación no es sino la puesta en alternativa de dos o más oraciones, combinada con sus posibles negaciones. La alternativa, pues, puede ser incluyente, excluyente o convertirse en una conjunción, pudiendo a su vez operar negativamente.

\section{Estructura Lógica}

Alternativa incluyente

Alternativa excluyente

Alternativa conjuntiva

Alternativa incluyente negativa

Alternativa excluyente negativa

Alternativa conjuntiva negativa

\section{Denominación Morfema}

Disyuntiva vel $\quad 0$

Disyuntiva aut 0

Copulativa $y$

Adversativa sino

Adversativa pero

Copulativa ni

\section{LA RELACIÓN PROPOSICIÓN/PERFORMATIVO EN LA COORDINA- CIÓN}

En este apartado intentaremos mostrar que la coordinación no es sólo coordinación de proposiciones sino de elementos lingüísticos más generales que la proposición, es decir, elementos lingüisticos que engloban a la proposición, que tienen a ésta como objeto. Uno de estos elementos es el performativo de la proposición. Por ello, creemos conveniente introducir sucinta pero esencialmente el concepto formal de performativo y por lo mismo de adverbial del performativo.

Entendemos por performativo la intención comunicativa del hablante, en oposición a la proposición, que es el objeto de esa intención, su contenido específico, (2). Ambos son necesarios, pues sería inútil pensar en un comunicado que no tuviera intención comunicativa, y ésta sin expresión concreta. De la conjunción de ambos nace la frase, que es la unidad mínima de comunicación, que cuenta además con eventuales presuposiciones.

En una frase como,

(2) Para el concepto de performativo, ver: JESPERSEN (1924), AUSTIN (1962), SEARLE (1969), DUCROT (1972), PARISI y ANTINUCCI (1973). 
(22) Ha salido el sol

el performativo es: Te comunico que... y la proposición: ha salido el sol, en donde el performativo está implícito; sin embargo, en

(23) Te prometo que te llevaré al cine

el performativo adquiere proyección léxica, te prometo, siendo su proposición, te llevaré al cine.

A veces, el performativo contradice los signos externos para conseguir resultados más sofisticados, como en

¿Me pasas la sal?

en donde el performativo, evidentemente, no es de pregunta sino de ruego. Y así, sucesivamente, nos adentraríamos en la maraña y complejidad de los performativos, que no forman parte de nuestro estudio sino tangencialmente.

Ahora bien, estructuralmente puede haber elementos de la proposición que no forman parte de la intención comunicativa, sino que estén por encima de ella. Recordemos el caso del adverbio probablemente tratado por RUWET (1968) y SCHREIBER (1971); y más acertadamente por ROSS (1970) y PUGLIELLI y PARISI (1975). Una frase como

(25) Pepe duerme, probablemente

frente a la frase

(26) Pepe duerme tranquilamente

pone de relieve que el adverbio probablemente incide en la frase de manera distinta que tranquilamente. La frase (25) podría ser parafraseada por algo asi como: Con valor de probabilidad comunico que Pepe duerme; mientras (26) permite ser parafraseada, por, comunico que Pepe duerme con tranquilidad, en donde vemos que en (25) el adverbio incide sobre el performativo informativo, mientras que en (26) el adverbio está dominado por el performativo y forma parte de la proposición. Es decir, probablemente es una especie de valoración que se hace sobre la comunicación; se valora como altamente probable lo que se comunica, que Pepe duerme; y contrariamente, el adverbio tranquilamente me relata una modalidad del sueño de Pepe. 
Pues bien, el primer caso es un adverbial del performativo, por cuanto es un elemento de la frase que domina al performativo y que no es dominado por él, y por lo mismo no forma parte de la proposición.

Dicho esto, creemos que la coordinación responde en parte a una coordinación no de proposiciones sino de performativos; consecuentemente, el elemento predicativo que coordine los performativos, los dominará, configurándose, pues, la estructura adverbial del performativo. Este hecho estructural lo queremos comprobar en toda la coordinación, es decir, en las disyuntivas, adversativas y copulativas.

\subsection{Disyuntivas}

Tal como hemos expuesto, la disyunción'se presenta bajo la forma de alternativa incluyente o excluyente. El ejemplo que hemos considerado como alternativa incluyente es,

(27) Tienen derecho a pensión los empleados con más de 30 años de servicio o con más de 65 años de edad.

Al ser la disyuntiva del tipo incluyente, la paráfrasis correcta que explicitara los performativos debería decir,

(28) La alternativa, te comunico que tienen derecho a pensión los empleados con más de 30 años de servicio incluye la alternativa, te comunico que tienen derecho a pensión los empleados con más de 65 años de edad.

La existencia, pues, de dos performativos en la alternativa incluyente implica a nivel estructural que el relacionante disyuntivo ponga en conjunción a los dos performativos y no a las dos proposiciones exclusivamente, adquiriendo la forma de adverbial del performativo

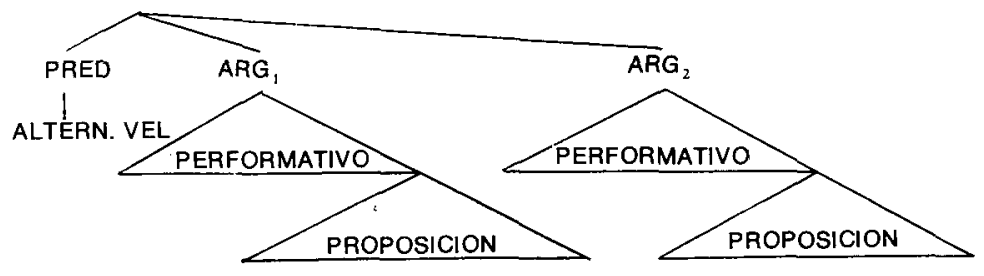

Sin embargo, en el caso de la alternativa excluyente no concurre el mismo hecho estructural, ya que una frase como, 
(29) Iré al cine o a los toros, para pasar la tarde

no puede ser parafraseada por: La alternativa, te comunico que iré al cine excluye la alternativa, te comunico que iré a los toros, lo que muestra que éste es un caso adverbial de la proposición y no del performativo.

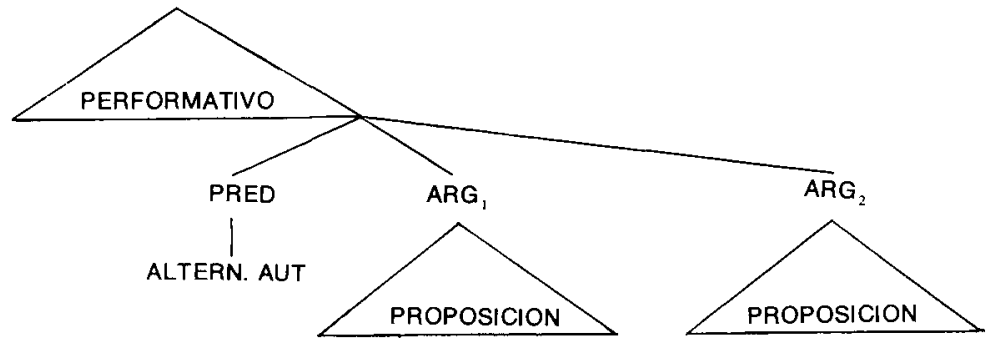

\subsection{Adversativas}

Las oraciones adversativas se presentan bajo dos formas, como negación de la alternativa excluyente y como negación de la alternativa incluyente, representadas respectivamente por los morfemas pero y sino. El primer tipo genera frases como,

(30) Juan estudió pero ¿aprobó?

en donde se evidencian dos performativos, uno que afirma que Juan estudió y el otro que cuestiona los resultados finales; es decir, la primera proposición tiene la intención de informar sobre algo, mientras que la segunda pide información.

La formalización, pues, de frases adversativas de este tipo implica la existencia de dos performativos relacionados adverbialmente por la conjunción coordinante.

Por su parte, la forma adversativa sino, no genera frases adverbiales del performativo sino de la proposición, ya que la frase,

(31) No retrocederemos sino que atacaremos

no permite la lectura que daría el adverbial del performativo: te comunico que no retrocederemos o te comunico que atacaremos, sino que se adecúa a la interpretación adverbial de la proposición: te comunico que no retrocederemos sino que atacaremos. 


\subsection{Copulativas}

Por último, las oraciones copulativas se pueden estructurar como adición de performativos, así en el ejemplo,

(32) - ¿Qué hay que hacer para ganar?

- Para ganar la prueba hay que subir la montaña y bajarla.

La respuesta dada consta de dos actos performativos; se dice que hay que subir la montaña, que hay que bajarla y que ambas comunicaciones deben añadirse, adicionarse, de manera que no hay ninguna intención comunicativa sobre la conjunción $y$, pues no entra a formar parte ni de la primera comunicación ni de la segunda, siendo ésta el elemento copulativo que adiciona los dos performativos.

La existencia de dos performativos en la estructura copulativa se hace más patente en los casos en que optemos por coordinar dos frases con performativos cualitativamente diferentes, así en una frase como,

(33) Juan se fue a las Fallas con Maria y iViva la Pepa!

constatamos que el primer performativo informa y el segundo, cualitativamente distinto, lanza una exclamación. Evidentemente, ninguno de los dos puede apropiarse a la conjunción y como formando parte de su proposición, sino que se percibe claramente cómo ambas intenciones comunicativas se interrelacionan por la acción de la conjunción copulativa $y$, que es un predicado adverbial del performativo.

Sin embargo, conviene no confundir los límites de nuestra afirmación, que se refiere exclusivamente a frases completas coordinadas y no a la posibilidad de coordinación de elementos internos de la proposición, en cuyo caso ya no se trata de coordinación de oraciones o frases, sino de coordinación de sintagmas. Una frase como,

(34) Tienen derecho a pensión los empleados con más de 30 años de servicio y 65 años de edad

en donde se coordinan sólo unidades sintagmáticas que son objeto de un único acto performativo, comunicar que tienen derecho a pensión los empleados que cumplan las dos condiciones.

En este caso de coordinación sintagmática la estructura es de adverbial de proposición, 


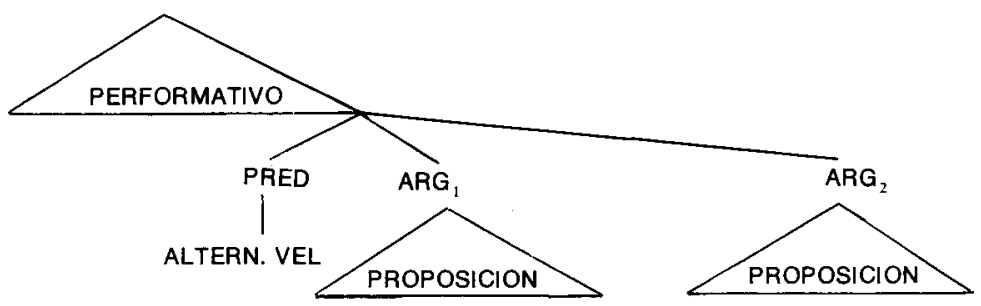

Quiero, por último, llamar la atención sobre un caso del tipo descrito, y que, tal vez, sirva para ampliar la estructura coordinada a otros ámbitos hasta ahora poco explicados. Una frase como

¿Pedro se marcha con Julia?

tal vez tenga su explicación semántica en una estructura coordinada pero adverbial de la proposición y no del performativo. Efectivamente, nos encontramos con una sola pregunta, por tanto con un sólo performativo. Se pregunta si se marchó Pedro con Julia. Ahora bien, ¿qué estructura conferimos a la proposición? La respuesta de CASTELFRANCHI, PARISI y CRISARI (1974) parece acertada y confirma nuestra hipótesis general. Para ellos, la diferencia entre

(36) Pedro y Julia se marchan

y

(37) Pedro se marcha con Julia

estriba en que en (36) tenemos una coordinación que es adverbial del performativo

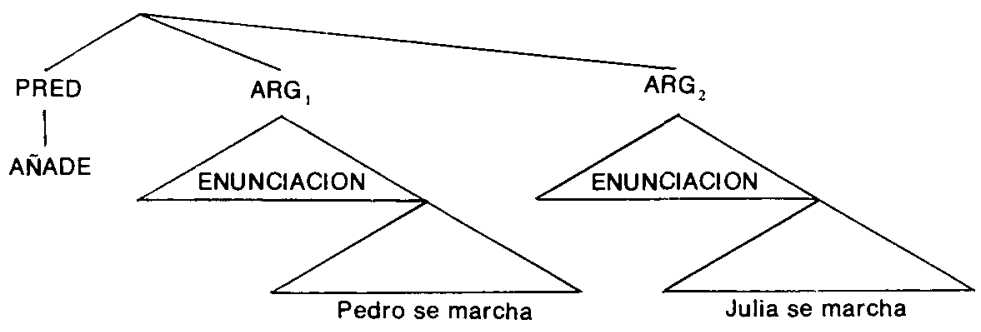


mientras que en (37) la coordinación es adverbial al núcleo de la proposición

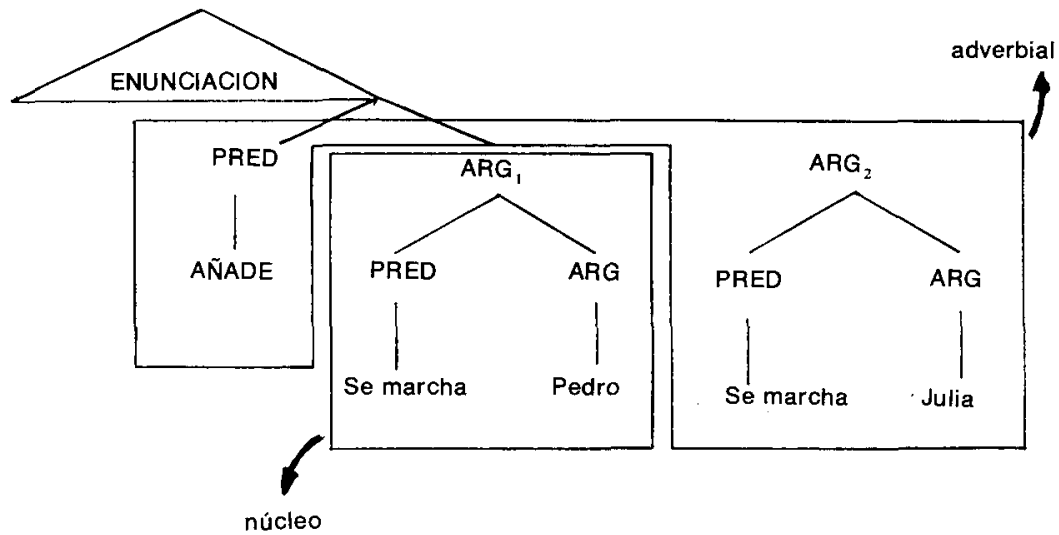

Precisamente, la diversa incidencia del adverbial produce el cambio de sentido que sentimos entre la frase (36) y (37). Con esto corroboramos, pues, que en la frase (36) existen

a) dos performativos

b) coordinación: estructura adverbial del performativo $y$ en la frase (37) existen

a) un performativo

b) coordinación: estructura adverbial de la proposición.

La posición, pues, que ocupa el predicado AÑADE respecto al performativo es la que conlleva la diferencia semántica entre ambas frases. En la frase (37), en donde el predicado AÑADE es dominado por el performativo, se expresa que Pedro se marcha, y añadimos que esa misma acción la ejecuta también otro actante, Julia. Al tratarse, pues, de una acción realizada conjuntamente, las acciones de Pedro y Julia no pueden ser independientes, sino que necesariamente tiene que existir una correspondencia entre ellas, de tiempo, lugar, modo, o de cualquier otro tipo, es decir, tienen la misma referencia pragmática. $Y$ este hecho queda representado en nuestro análisis, en cuanto que con Julia proyecta la estructura AÑADE: se marcha Julia, que es adverbial del núcleo Pedro se marcha, luego con la misma acción referencial.

Por el contrario, este tipo de referencia pragmática en las acciones no se encuentra en la frase (36), en donde la copulativa y no implica 
que las acciones tengan la misma referencia, ya que pueden darse en distintos tiempos, lugares o modos.

Con la frase (37), pues, denotamos una única acción ejecutada por dos actantes conjuntamente, por eso expresamos que Pedro se marcha con Julia; mientras que con la frase (36) decimos que Pedro se marcha y que Juan se marcha, luego hacemos dos declaraciones, cada una semánticamente suficiente y que el hablante las une entre sí con la coordinación. Es decir, se me comunica que Pedro se marcha y se me comunica que Juan se marcha, en consecuencia, se hacen dos actos de intención comunicativa, dos performativos.

Abundando en las diferencias existentes entre las frases (36) y (37) y como prueba de corrección de nuestro análisis podemos realizar el test de la escisión, en base al cual son escindibles sólo las partes que están bajo el dominio del performativo de una frase. Según esto, podemos laminar con Julia de la frase (37), obteniendo

\section{(38) Es con Julia con quien Pedro se marcha}

mientras que al separar y Julia en la frase (36) el resultado da una expresión agramatical

(39) *Es y Julia que Pedro se marchan

En el primer caso, la escisión se hace posible porque el elemento laminado tiene el mismo performativo que el resto de la proposición; y en el segundo caso, la imposibilidad de laminación se debe a que dicho elemento proposicional está bajo un performativo diferente.

Recapitulando, podemos afirmar que las condiciones estructurales que definen la preposición con, como coordinante adverbial de la proposición, son

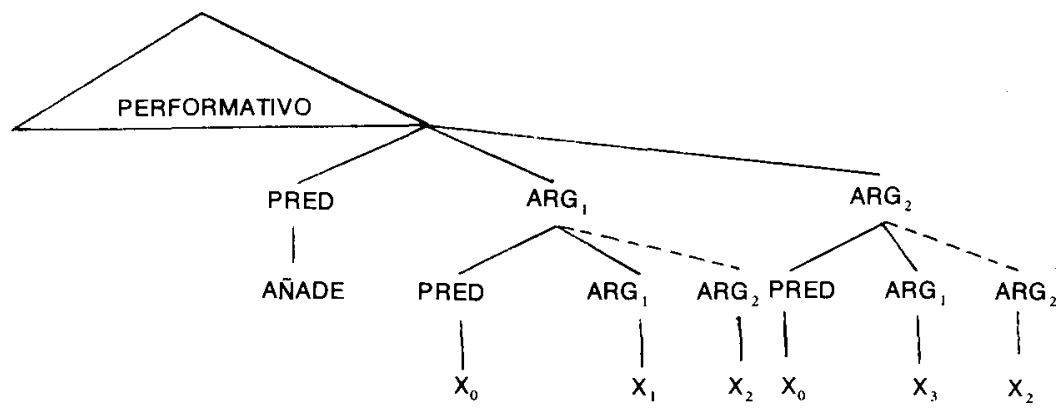


en donde la acción del PREDICADO es la misma y los ARGUMENTOS también son correferenciales a excepción de uno. $Y$ es este ARG no idéntico, el que se proyecta en un nominal precedido por la preposición con.

Podemos, pues, concluir este apartado diciendo que en la coordinación la disyuntiva se presenta bajo dos formas estructurales en relación al performativo, como adverbial del performativo en la disyuntiva incluyente y como adverbial de la proposición en la disyuntiva excluyente. Asimismo la adversativa presenta la misma ambivalencia, pues la adversativa pero es adverbial del performativo y la adversativa sino adverbial de la proposición; por último, la copulativa corresponde a la estructura adverbial del performativo, aunque puede darse dicha estructura como adverbial de la proposición en determinados casos, como el de la preposición con.

Según esto, podemos definir la coordinación como la estructura oracional en alternativa que presenta dos modalidades, la adverbial del performativo o de la proposición.

2.4. Los tipos estructurales adverbial del performativo y adverbial de la proposición

TIPO

1. Disyuntiva vel

2. Disyuntiva aut

3. Adversativa pero

4. Adversativa sino

5. Copulativa
ESTRUCTURA PREDICATIVA

\author{
ALTERNATIVA VEL \\ ALTERNATIVA AUT \\ NEG/ALTERNATIVA AUT \\ NEG/ALTERNATIVA VEL $(p, N E G q)$ \\ NEG/ALTERNATIVA VEL (NEG $p, N E G q$ )
}

Los tipos 1, 3 y 5 son adverbiales del performativo, como ya mostramos, y los tipos 2 y 4 son adverbiales de la proposición. Esta distinción estructural anuncia hechos lingüísticos relevantes: la heterogeneidad performativa en los típos 1, 3 y 5 frente a la homogeneidad y supletoriedad en los tipos 2 y 4.

Efectivamente, sólo los tipos adverbiales del performativo permiten la mixtificación de performativos cualitativamente diferentes en una misma frase, así, por ejemplo, la coordinación de la enunciación con el mandato; de la enunciación con la interrogación, etc.

Los tipos 1, 3 y 5 pueden estar representados por las siguientes frases. Como disyuntiva incluyente, 
(40) La historia de Demetrio Aquilea o ¿Cómo ganar batallas perdidas? como adversativa pero

(41) Juan estudio pero ¿aprobó?

como copulativa

(42) Juan se fue a las Fallas con María y iViva la Pepa!

El concepto que aglutina estos tres tipos coordinantes puede ser el de la inclusión: inclusión hay en la alternativa incluyente, en la negación de la alternativa excluyente, y en el sentido conjuntivo de la copulativa. Por contra, el concepto que aglutina los tipos 2 y 4 es el de la exclusión, que se da en la alternativa excluyente y en la negación de la alternativa incluyente. Por ello, el tipo incluyente permite frases del modelo «la»comunicación $p$ incluye la comunicación q», mientras no puede generarse «la comunicación p excluye la comunicación q» sino más bien "comunico que $p$ excluye q". Con esto vemos que la dualidad performativa es sólo propiedad del tipo incluyente y que de su carácter dual se origina la capacidad de heterogeneidad performativa.

Por su parte, los tipos excluyentes 2 y 4 mantienen necesariamente un hilo argumental común que les impide duplicar los performativos y por ello su no heterogeneidad. Este hilo argumental común puede darse a niveles proposicionales, repitiendo algún sintagma "vas al cine o a los toros" que tiene un sujeto común, o bien, puede darse a niveles presuposicionales o implícitos, así en,

\section{O llovió o Celestino ganó}

en donde ambas acciones están referidas a "un mismo campeonato» en el que "o bien llovió» o en su defecto se da por seguro la victoria de Celestino.

Esta comunidad argumental que presentan el tipo 2 y 4 nos lleva a considerar que se da en razón de la necesidad de que las proposiciones sean términos contrapuestos o excluyentes, es decir, términos supletorios. Así, el tipo 2, o dilema, presenta varias alternativas a elección de una; y eso significa que un término hace las veces del otro, suple al otro, tiene capacidad de sustituirle; por eso la bolsa es supletoria de la vida. Y en el tipo 4, en donde se afirma «no estudiarás en la Facultad sino que te quedarás en casa", el segundo término sustituye también al primero. Por ello, podríamos afirmar que lo común en los tipos 2 y 4 es que son términos supletorios. Estos elementos sustituibles, efectivamente, deben ser homogéneos, ya que uno es capaz de hacer las veces 
del otro, luego imposibilitan el tener performativos cualitativamente diferentes.

\section{LA YUXTAPOSICIÓN Y LAS DISTRIBUTIVAS}

\subsection{Estructura formal de la yuxtaposición}

Consideremos la frase,

(44) Se despidió de todos, nos miró por última vez, forzó una sonrisa y desapareció

cuya estructura aproximada puede ser la siguiente

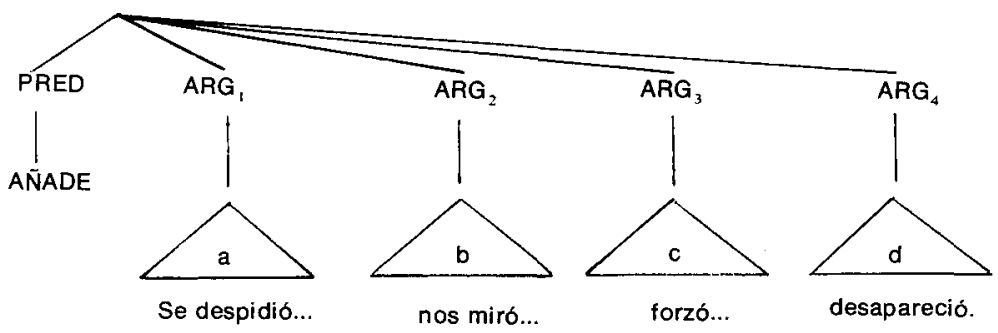

La relación entre las oraciones $a-b-c$ es igual a la existente entre las oraciones $c-d$, pues en ambos casos se añade una oración a la otra hasta formar una enumeración completa. La única diferencia a reseñar es que entre $a-b-c$ el relacionante no al canza a proyectarse en sonidos y entre $c-d$ se proyecta la conjunción $y$, sin que por ello se modifique la relación semántica entre las cuatro oraciones, la adición. Bien que la copulativa $y$ indique complementariamente que se trata del último elemento de la serie.

Según esto, la estructura copulativa puede utilizar dos recursos equivalentes al hacer la enumeración, la pausa y la conjunción y.

Dada la significación igual de la pausa y de la conjunción y en las oraciones copulativas, podemos adelantar la hipótesis de trabajo de que en la yuxtaposición, cuyo relacionante es la pausa, la estructura semántica responde a la mera adición, lo que nos conduce a la estructura léxico-semántica de la coordinación copulativa: la adición de performativos. 
Según ello, una frase como,

(45) Llegué, vi, venci

se configura semánticamente en

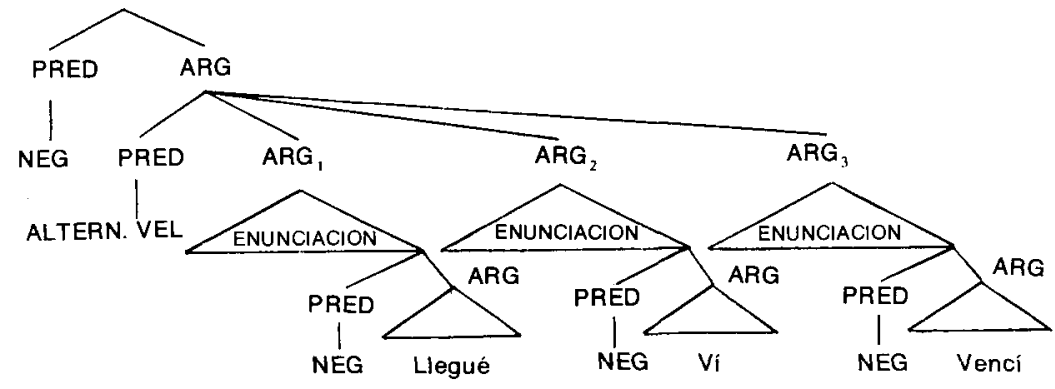

cuya forma abreviada es

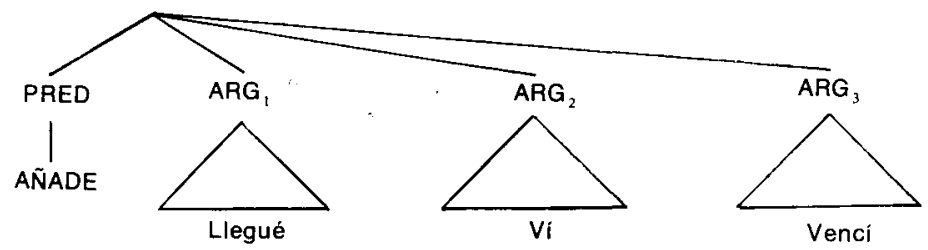

Para poder confirmar la hipótesis enunciada, hemos de hacer una aproximación al análisis componencial de la estructura asindética del tipo expuesto.

Efectivamente, en la yuxtaposición encontramos una serie plurimembre de oraciones que mantienen la cohesión en virtud de unos fenómenos fonológicos, que, por no llegar a la cristalización léxica en morfemas, permanecen, por desgracia, vagamente analizados.

Ante la carencia de morfemas que imbriquen la seriación asindétića, los autores convienen en afirmar que la yuxtaposición se construye mentalmente como una unidad, y algunos la circunscriben acertadamente a una unidad tonal (GILI GAYA, 1950).

Ahora bien, en qué consiste esta unidad tonal, es la pregunta exacta que abre paso al análisis componencial del significado de la yuxtaposi- 
ción. Para ello, consideremos que una oración yuxtapuesta contiene, al menos, un primer miembro u oración y un segundo miembro unido al anterior por una pausa natural.

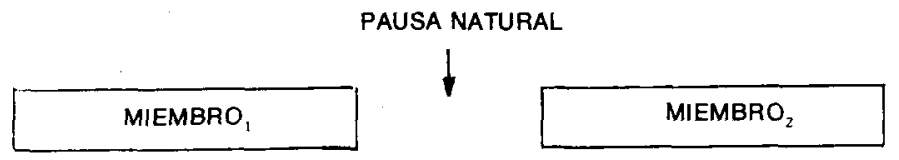

Los dos miembros de la yuxtaposición presentan en su inicio y en su fin un tonema inicial de ataque y un tonema final de cadencia (3)

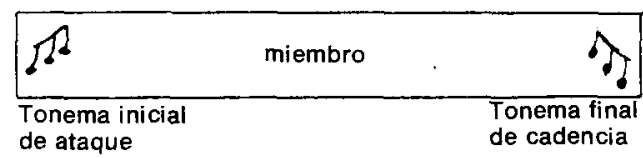

quedando, pues, completado el esquema de la yuxtaposición en PAUSA NATURAL
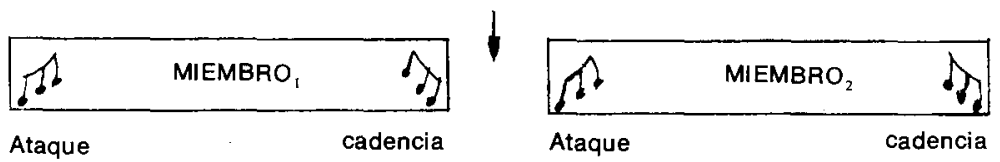

Según esto, la yuxtaposición responde a una estructura plurimembre de dos o más miembros oracionales compuestos cada uno de una melodía circunscrita en su inicio por tonemas que configuran el ataque inicial de la misma, y en su final por tonemas que configuran la cadencia final; y unidos, los miembros, por pausas naturales de una duración media, entre 30 y 40 c.s.

La naturaleza fonológica de la pausa es clara y debe oponerse tanto a los silencios no voluntarios que jalonan la corriente sonora, como a las vacilaciones. De hecho, en el análisis de la corriente sonora se detectan silencios de diversa etiología, oclusiones, pausas rítmicas, etc., que no son sentidas como pausas o momento de detención del

(3) Para la descripción fonológica de dicho tonema véase GILI GAYA (1950). 
significado que se transmite, $y$, por ello, no pueden ser consideradas como voluntarias; por el contrario, la pausa en la yuxtaposición es una pausa consciente, intencional.

Por otro lado, debe oponerse también a la pausa de vacilación, que como describió BOOMER (1965) tiende a aparecer hacia el principio de los grupos tonales, frecuentemente después de la primera palabra, mientras que la pausa de la yuxtaposición se intercala entre dos grupos tonales.

Ahora bien, todos estos elementos constitutivos de la yuxtaposición: miembros oracionales, tonemas de ataque y cadencia, y pausas naturales, forman una unidad tonal en virtud de una ley estructural de equipolencia gramatical que los cohesiona; y no en virtud de ningún morfema, como sucede en las oraciones no asindéticas. Esta ley estructural sustituye, pues, enterizamente la funcionalidad del morfema conjuntivo, y puede ser enunciada así:

«En la producción de una oración yuxtapuesta, la entonación que se va a elegir para el ataque del $2 .^{\circ}$ miembro está en relación directa con la cadencia con que ha finalizado la entonación del miembro anterior; $y$, lógicamente, la entonación que se elija para el $1 .^{\circ}$ miembro ha de prever equipolentemente las entonaciones subsiguientes de los miembros posteriores oracionales.i Luego, en conclusión, toda yuxtaposición tiene una antepreparación unitaria en el cerebro, antes de producirse su actuación, similar a la que postula, mutatis mutandis, HALLIDAY (1967) para los grupos tonales, que en nuestro caso serían grupos tonales oracionales.

Esta equipolencia fonológica que hemos enunciado debe extenderse también a la sintaxis y semántica de los miembros constituyentes de la yuxtaposición, ya que dichos segmentos o miembros deben ser iguales, paralelos y del mismo sentido, formando una unidad por suma o adición de miembros equipolentes de modo que el origen de cada uno coincida con el extremo del precedente; resultando que el segmento definido por el origen del primero y el extremo del último sea la suma de todos los segmentos.

Resumiendo lo dicho hasta aquí, entendemos que la yuxtaposición presenta la estructura léxico-semántica de la copulativa y que el análisis componencial de la misma está configurado por una pausa intencional entre sus miembros, y que, a su vez, éstos forman una unidad tonal, regida por una ley estructural.

\subsection{La yuxtaposición y la inferencia}

Con todo, parece necesario hacer referencia a una cuestión siempre 
presente en el tratamiento del asíndeton oracional: las oraciones yuxtapuestas con significados causales, temporales, concesivos, sustantivos, condicionales, copulativos, adversativos, etc.

Nos hallamos, una vez más, ante un hecho denunciado repetidamente en el análisis habitual de los relacionantes: la imprecisión, por parte del analista, del objeto de su análisis. En nuestra introducción hemos definido explícitamente el objeto del análisis y lo hemos circunscrito al análisis del valor léxico de los relacionantes, es decir, id quod suficit et requiritur para que se dé el significado léxico. Esto se contrapone a aquellos significados complementados por los conocimientos que ya posee el hablante-oyente y que, gracias a las llamadas operaciones inferenciales (CASTELFRANCHI, PARISI 1980), enriquecen los valores léxicos con que se transmite la comunicación o frase. A este conjunto de saberes adicionales o complementados les denominamos enciclopedia, frente al valor léxico o indispensable, equivalente al mínimo común denominador de todos los valores.

Sin esta distinción previa, parece imposible atinar en el estudio de la yuxtaposición, pues, nos encontraríamos conque una estructura es a la vez coordinada y subordinada, tiene a veces miembros equipolentes y otras veces no, etc.; con lo que sucedería, por contagio, que tampoco podríamos discernir, en general, aquello que separa la coordinación de la subordinación.

Consideremos, pues, el hecho en cuestión. El que una frase asindética como,

\section{Hace frío, llévate el abrigo}

se entienda como consecutiva obliga a hacer una doble consideración: primero, que el hablante no genera una estructura consecutiva, sino yuxtapuesta, es decir, que cumple los requisitos de unidad tonal: pausa intencional y ley estructural tonal entre los miembros que sustituyen el morfema léxico; segundo, que esta frase puede ser interpretada por el oyente como consecutiva. $O$ bien, con otros ejemplos, se puede derivar desde una yuxtapuesta a una condicional, causal, etc.; e incluso, a veces, puede ser ambigua su interpretación, ora adversativa, ora concesiva.

Como ya adelantamos, la dispersión de sentidos que puede presentar la yuxtaposición corresponde a los valores enciclopédicos que cada oyente añade automáticamente haciendo inferencia de los conocimientos almacenados en su memoria culturalmente o contextualmente. Estas incorporaciones automáticas producen el hecho de que una frase no signifique como uno, sino que signifique como dos, tres o cuatro, 
según le esté permitido al oyente hacer una, dos o tres inferencias. Como es lógico, estos valores inferenciables, que llamamos enciclopedia, no son, ahora, el objeto de nuestro análisis. Y creemos que previamente debe conocerse el valor léxico y luego, en su caso, acometer el análisis del valor enciclopédico; siendo, el primero, condición indispensable para el segundo.

A este respecto es ilustrativo el ejemplo siguiente,

\section{(47) Emilita no corre, vuela}

(48) Emilita no corre sino vuela

\section{(49) Emilita no corre sino salta}

Si operáramos con criterios enciclopédicos, es decir, sentidos complementados, podríamos afirmar que la frase (48) es sinónimo de (47), y en virtud de la sinonimia afirmar que (47) es adversativa, cuando estructuralmente no lo es. Si seguimos operando así, también sentimos que aunque (48) y (49) son adversativas estructuralmente, no son iguales en sus sentidos últimos, porque en (48) no corre y vuela tienen la misma referencia pragmática, se dicen de la misma acción de correr, mientras que en (49) no corre y salta no tienen la misma referencia. Por consiguiente, la frase (48) significaría que Emilita corre velozmente, lo que nos llevaría a analizar una oración adversativa como una oración simple, en virtud de los conocimientos adicionados inferencialmente.

Estos trasiegos que permiten los sentidos complementados o enciclopédicos no deben operar al analizar los estrictos valores léxicos de los relacionantes, ya que al mezclarse los objetivos del análisis ocurriria que a veces se examinarían los hechos con criterios léxicos, y a veces con criterios enciclopédicos, dando lugar a conclusiones falsas y confusas, debido al cambio del método analítico.

Concluyendo, pues, afirmamos que léxicamente una estructura oracional yuxtapuesta no debe ser tratada en el inicio del análisis semántico como una estructura causal, condicional, etc., aunque la descripción analítica que de ella se haga debe ser tal que permita, con facilidad, el paso a la restricción de sentido que las inferencias ericiclopédicas puedan producir. En una palabra, todo buen análisis léxicosemántico de la yuxtaposición debe reflejar y explicar por qué se puede hacer la inferencia concesiva, causal, etc.

A este respecto y excepcionalmente, pues no es nuestro propósito indagar valores enciclopédicos, creemos oportuno con un solo ejem- 
plo, poner de relieve cómo nuestro sistema operacional permite con facilidad el paso de la yuxtaposición a la coordinación y subordinación. Para ello, tomaremos una frase yuxtapuesta que permite ser restringida al valor adversativo y concesivo, proceso por otro lado muy frecuente en la yuxtaposición con miembro negativo. Consideremos

(50) El lo dice; no le haremos caso

cuya descripción semántica corresponde a la estructura asindética

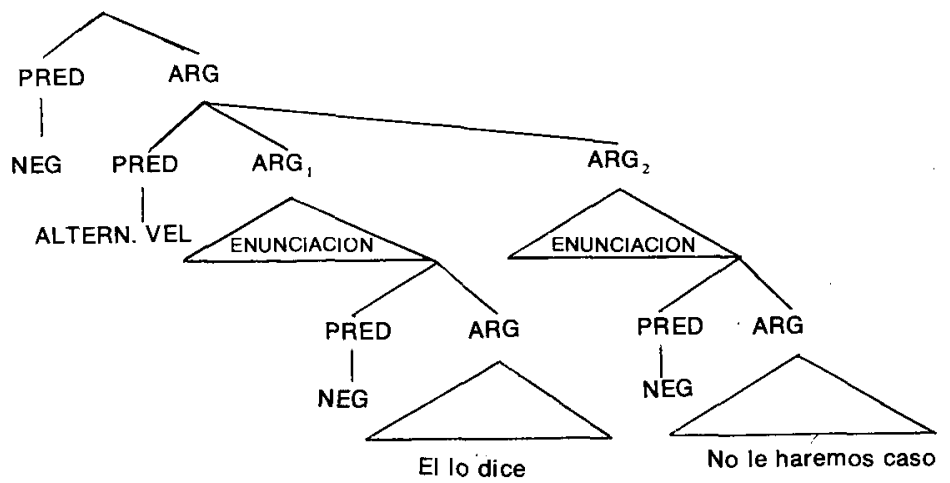

cuya lectura es Niego que él no lo dice o que $(n o$, no) le haremos caso. (Nota: las dos negaciones del $\mathrm{ARG}_{2}$ se anulan, dando paso a la afirmación.)

Ahora queremos poner de relieve cómo desde una estructura así, la enciclopedia puede restringir el sentido amplio que ofrece la yuxtaposición y convertirlo en un sentido inferencial adversativo; bastaria, para ello, suprimir las dos operaciones NEG dominadas por el performativo, quedando

(51) El lo dice pero no le haremos caso

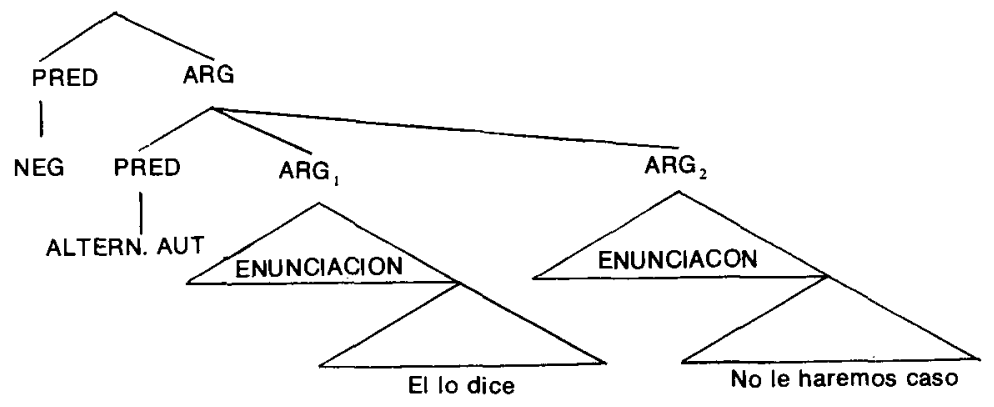


en donde se han suprimido ambas NEG; y cuya lectura es: Te comunico que él lo dice no excluye que te comunique que no le haremos caso.

El paso de la yuxtapuesta a la concesiva se da también con suma facilidad como va a evidenciar el cambio estructural siguiente.

La frase, en este supuesto, toma el sentido inferencial de

(52) El lo dice aunque no le haremos caso

Para educir este sentido basta que la mente omita una sola de las negaciones existentes en la estructura que corresponde a la frase (50), $y$, además, restrinja el operador de adición ALTERNATIVA al operador CAUSA, que es semánticamente más preciso; según ello obtendríamos,

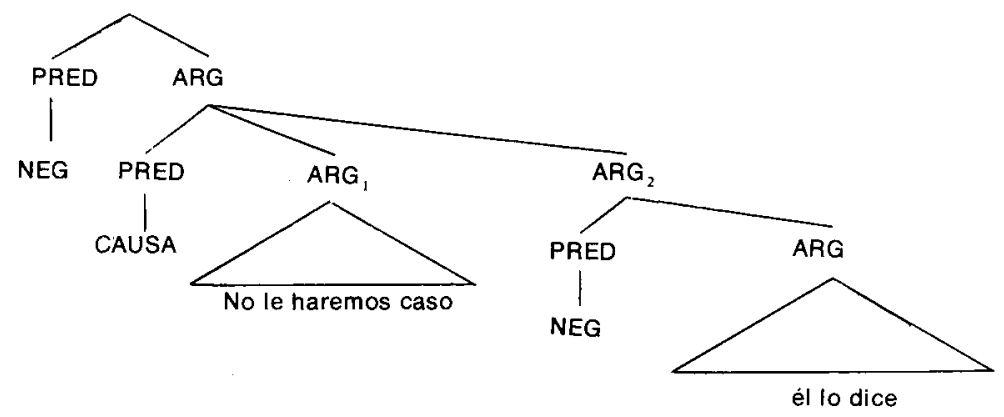

cuya lectura es: que nosotros no le hagamos caso no causa que él no lo diga, observando que el cambio estructural realizado da como resultado la estructura semántica de la concesiva: NEG/CAUSA/NEG.

Por todo ello, vemos cómo desde

Yuxtapuesta: NEG, ALTERN. VEL $\left\{\begin{array}{l}\text { NEG } \\ \text { NEG }\end{array}\right.$

se cambia a

Adversativa: NEG, ALTERN. AUT $\left\{\begin{array}{l}\text { NEG } \\ \text { NEG }\end{array}\right.$

o se cambia a

Concesiva: NEG, CAUSA

$\left\{\begin{array}{l}\text { NEG } \\ N E G\end{array}\right.$ 
Estos serían, pues, los predicados semánticos NEG que dejarían de operar, según se infiera un sentido adversativo o concesivo y en este último caso con la restricción predicativa del operador CAUSA.

Además, es cabal y justo señalar que el modelo expuesto permite y posibilita el paso de la yuxtaposición a la adversativa o a la concesiva, dado que las tres estructuras oracionales presentan modelos muy equiparables y transferibles.

Por último, queremos llamar la atención sobre lo desacertado del intento de algunos gramáticos al considerar yustapuestas frases sustantivas del tipo

(53) Me pidió fueras a verles

o concesivas

(54) No le haremos caso diga lo que diga

que no cumplen las condiciones expuestas para la yuxtaposición: en (53) no hay pausa intencional y en (54), aún en el supuesto de que se enunciara con pausa, no cumpliría la ley estructural fonológica de la yuxtaposición basada en la equipolencia de los miembros; además se da anticadencia. $Y$ tampoco sintácticamente hay equivalencia temporal IND./SUB. Estos casos deben ser explicados más bien por los morfemas $\varnothing$, implícitos, que, aunque no alcanzan una interpretación fonética y fonológica, están realmente operando en la frase, silenciosamente.

\subsection{Las distributivas}

Las oraciones distributivas, además de presentar la relación formal paratáctica con una pausa natural, señalizan su carácter distributivo por medio de elementos correlativos o iguales, en ambas oraciones.

(55) Unos bailaban, otros cantaban

(56) Bien se agitaban como locos, bien permanecian inmóviles.

Normalmente, los elementos correlativos son determinantes, adverbios, locuciones adverbiales, conjunciones, etc.

La nexuación se proyecta como una pausa natural y cumple además la ley estructural equipolente, lo que muestra que las distributivas pertenecen a la clase yuxtapuesta. La estructura, pues, semántica será la de la adición, es decir, copulativa. 


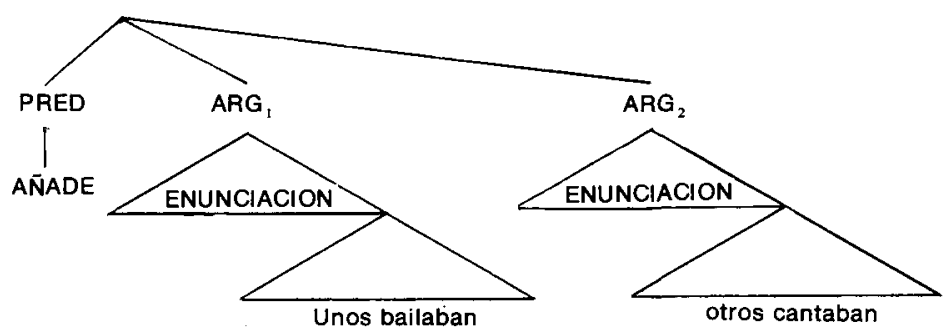

El hecho de que a veces los elementos correlativos sean iguales, ya... ya, ora... ora, ha llevado erróneamente a determinados autores a considerar este tipo de distributivas como disyuntivas, así

(57) Bien jugaban, bien Ieian

puede alcanzar evidentemente un sentido disyuntivo exclusivo, aunque no necesariamente. Ahora bien, el sentido exclusivo le viene dado por la simultaneidad de las acciones - conocimiento inducido inferencialmente- que impide jugar y leer a la vez; por tanto son excluyentes. Pero no siempre tenemos un sentido excluyente, como en

(58) Bien recogieron leña, bien asaron las chuletas

en donde se enumeran unas acciones "que realizaron los excursionistas" sin ser necesariamente excluyentes, ya que algunos excursionistas pudieron hacer ambas.

El sentido de disyunción excluyente que puede conseguir la yuxtapuesta distributiva es un caso más de lo expuesto anteriormente sobre la extensión semántica que puede alcanzar la yuxtaposición, debido a los sentidos inferenciables que pueden añadirse. Dentro de nuestro modelo, el paso del sentido yuxtapuesto al disyuntivo se puede hacer de una manera totalmente natural, bastando realizar la restricción de todos los operadores negativos

YUXTAPOSICIÓN: NEG, ALTERN. VEL $\left\{\begin{array}{c}\text { NEG } \\ \text { NEG }\end{array}\right.$

DISYUNCIÓN: N⿴EQ, ALTERN. AUT $\left\{\begin{array}{l}\text { NEG } \\ \text { NEG }\end{array}\right.$ 
obteniendo con ello el sentido disyuntivo excluyente.

Por todo ello, pensamos conveniente no situar a las distributivas a caballo de las copulativas y disyuntivas - que propiamente no resuelve nada- sino concluir que son oraciones asindéticas cuya descripción semántica corresponde a la de las oraciones copulativas. Tanto, pues, las oraciones yuxtapuestas, como las distributivas - que son una variante de las mismas - tienen una configuración de predicados del tipo:

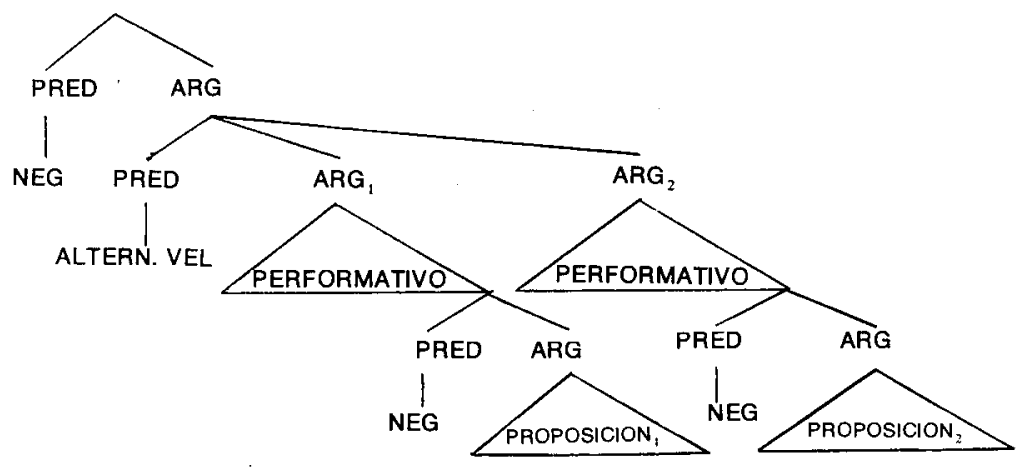

en donde

CONFIGURACIÓN DE PREDICADOS

COPULATIVA: NEG, ALTERN. VEL $\quad\left\{\begin{array}{l}\text { NEG } \\ \text { NEG }\end{array} \Leftrightarrow y \circ\right.$ pausa natural

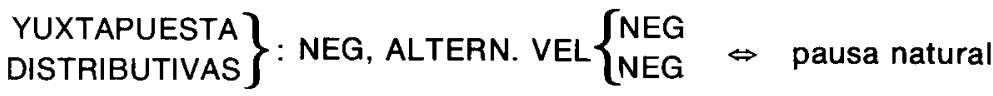

En el caso de las distributivas las proposiciones 1 y 2 tienen elementos correlativos. 


\section{REFERENCIAS BIBLIOGRÁFICAS}

ANSCOMBRE, G.E.M. y DUCROT, O.: (1977) “Deux mais en français? », Lingua, 43, pp. 23-40.

AUSTIN, J.L.: (1962) How to do things with words. Londres: - Oxford University Press.

BOOMER, D.S.: (1965) «Hesitation pauses and juncture pauses in speech", en Language and Speech, 8, 148-58.

BOSQUE, I.: (1980) Sobre la negación, Madrid: Cátedra.

CASTELFRANCHI, C.: (1975) "Una mente enciclopedica", en Studi per un modello del linguaggio. Roma: CNR

CASTELFRANCHI, C., PARISI, D.: (1980) Linguaggio, conoscenze e scopi. Bologna: II Mulino.

CASTELFRANCHI, C., PARISI, D., CRISARI, M.: (1974) "Con" en, Fenomeni Morfologici e Sintattici nell'italiano contemporaneo, I, 27-46. Roma: Bulzoni.

CHOMSKY, N.A.: (1957) Sintactic Structures, La Haya: Mouton.

DUCROT, O.: (1972) Dire et ne pas dire. Principes de Sémantique. París: Hermann.

FAUCONNIER, G.: (1975) «Pragmatics Scales and Logical Structure», Linguistic Inquiry V1, págs. 353-75.

GILI GAYA, G.: (1950) “Fonología del período asindético», en Estudios dedicados a D. Ramón Menéndez Pidal, I, 57-67. Madrid.

HALLIDAY, M.A.K.: (1967) Intonation and Grammar in British English. 
(Janua Linguarum, Series Practica, 48) La Haya: Mouton.

JESPERSEN, O.: (1924) The Philosophy of Language. Nueva York: Harper y Row.

PARISI, D., ANTINUCCI, F.: (1973) Elementi di grammatica. Turín: Boringhieri.

PARISI, D., ANTINUCCI, F., CRISARI, M.: (1975) “'Dovere', 'Potere', 'Volere' e il futuro dei verbi», en Studi per un modello del linguaggio. Roma: CNR.

POSNER, R.: (1980) "Semantics and Pragmatics of Sentence Connectives in Natural Languaje» en J.R. SEARLE y otros (eds.) Speech Act Theory and Pragmatics. Reidel, págs. 169-203.

PUGLIELLI, A., PARISI, D.: (1975) "Avverbiali performativi» en Studi per un modello del linguaggio. Roma: CNR.

ROMÁN DEL CERRO, J.L.: (1981) El léxico base del castellano: Análisis estadístico y de contenido. Alicante: Publicaciones Caja Ahorros Provincial.

ROSS, J.R.: (1970) “On declarative sentences", en Readings in English Transformational Grammar, R. JACOBS y P. ROSENBAUM, eds. Waltham, Mass.: Ginn.

RUWET, N.: (1968) «Adverbs. A note of the question: Where do they all come from?". Ciclostilado.

SCHREIBER, P.A.: (1971) "Some contraints on the formation of English sentence adverbs", en Linguistic Inquiry, 2, 83.

SEARLE, J.: (1969) Speech Acts. Cambridge: University Press. 